\title{
Faculty Change from Within: The Creation of the WMSURE Program
}

\author{
Cheryl L. Dickter, College of William \& Mary \\ Anne H. Charity Hudley, University of California Santa Barbara \\ Hannah A. Franz, College of William \& Mary \\ Ebony A. Lambert, Virginia Commonwealth University
}

\begin{abstract}
Underrepresented students have less knowledge of research experiences available on campus and are less likely to feel supported by faculty than represented students. To address these issues and increase the number of underrepresented undergraduate researchers, faculty at the College of William \& Mary created the William \& Mary Scholars Undergraduate Research Experience (WMSURE). Communitybased and participatory research methods were used to work with students in developing research questions and in collecting and analyzing quantitative and qualitative data about their academic and personal experiences. This led to the development of academic and research advising services, workshops, faculty education, and research funding to support underrepresented students. This article evaluates the program. Results suggest that the WMSURE program has increased research opportunities and feelings of support on campus.
\end{abstract}

Keywords: mentoring, student programming, student support, undergraduate research, underrepresented students

doi: 110.18833/spur/2/1/6

\section{Purpose: Addressing the Need for the Program}

Undergraduate research has been shown to be a critical factor in addressing academic success by improving the quality of learning experiences for underrepresented students (e.g., Lopatto 2007). One benefit of conducting undergraduate research is having a close working relationship with a faculty member; indeed, students who have mentors achieve more and have better college experiences than those without mentors (Bearman et al. 2007; Clark, Harden, and Johnson 2000; Phinney et al. 2011). Previous research, however, has demonstrated that undergraduates from underrepresented racial (American Indian or Alaska Native, black or African American, Native Hawaiian or other Pacific Islander, multiracial) and ethnic (Hispanic or Latinx) backgrounds in the United States (National Institutes of Health 2015; National Science Foundation 2014) as well as students who are the first in their family to attend college (U.S. Department of Education 2018) are less likely to have research experiences in college than their peers (e.g., Russell, Hancock, and McCullough 2007). For the purposes of this article, underrepresented students are defined as those who self-identify with the racial and ethnic groups previously mentioned, as well as first-generation students.

The kind of mentoring experiences that can be forged through undergraduate research are especially important for underrepresented students. Faculty members who are themselves from underrepresented communities are ideal mentors for such students (Blake-Beard et al. 2011) but often find themselves stretched thin by other commitments. Because faculty from underrepresented communities are themselves underrepresented in the academy, they often find themselves in demand as research advisers. They, too, often require additional support (e.g., Laden and Hagedorn 2000). To complicate factors even more, at predominantly white institutions (PWIs), white faculty often lack ways to reach out to underrepresented students, even though underrepresented students may gain significant advantages from having white mentors 
(Dreher and Cox 1996; Ortiz-Walters and Gilson 2005; but see Frierson, Hargrove, and Lewis 1994; Smith, Smith, and Markham 2000). Underrepresented students, in turn, are often uncomfortable and sometimes dissuaded from approaching faculty about research opportunities and can feel isolated and unsupported at their institution. Educating faculty about ways to engage with and mentor students from disadvantaged backgrounds, then, can help support underrepresented undergraduates through quality research experiences and mentoring, and offer a way to improve the academic and social outcomes of underrepresented students. Improving these outcomes also can contribute to making more inclusive and equitable campuses and educational experiences for all students.

The College of William \& Mary is a public university in the southeastern United States with a nationally acclaimed undergraduate program. It boasts a moderate size, dedicated faculty and a distinctive history that fosters close interaction among students and teachers. Yet William \& Mary has a centuries-long history of reliance on slavery and the mistreatment of African American employees and students. William \& Mary has been successful in increasing the diversity of its undergraduate student body from 14 percent students of color in 2001 to 29 percent today. Eleven percent of William \& Mary undergraduates are the first in their families to go to college. One contributor to this achievement is the William \& Mary Scholars program. Established in 2002, it draws on institutional resources to provide approximately 40 to 60 in-state scholarships in each enrolling class to academically distinguished students who have overcome unusual adversity and/or are members of groups who contribute to campus diversity. Approximately 33 percent of current students who receive the William \& Mary Scholars award are first-generation students.

FIGURE 1. Overview of WMSURE Components

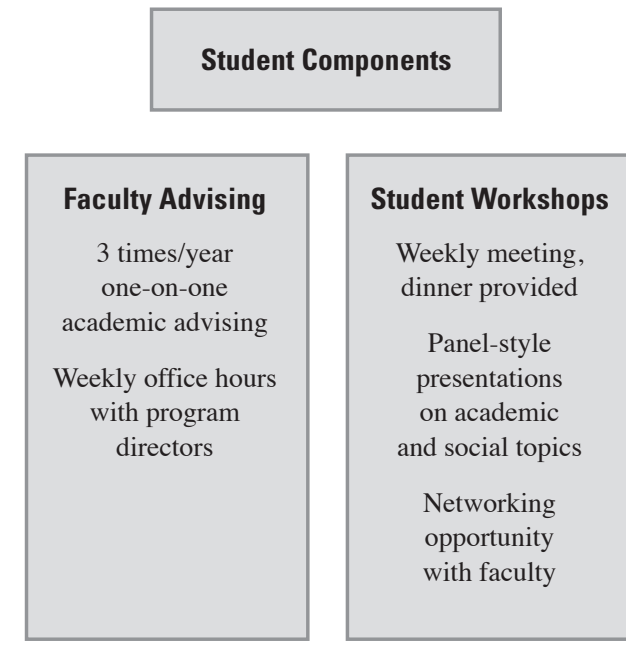

William \& Mary has the smallest black-white student gap in graduation rates among public universities in the nation. However, there is room for improvement in the number of William \& Mary Scholars who become undergraduate researchers. About 10 percent of William \& Mary students conduct senior honors theses, but only about 5 percent of African American students and about 3 percent of students who self-identify as Latinx or Hispanic (including those self-identifying as Chicanx) do so. There also are disparities in research experiences between first-generation and non-first-generation students: only 30.6 percent of William \& Mary first-generation students are involved in mentored research, compared to 40.8 percent of non-firstgeneration students. Underrepresented students at William \& Mary also report having less knowledge about research opportunities available on campus than white students and are less likely to feel supported and mentored by faculty.

To address these issues and ensure that underrepresented students are engaging in high-impact activities in college, faculty at William \& Mary created the William \& Mary Scholars Undergraduate Research Experience (WMSURE). The program's goal is to increase the number of underrepresented students engaging in undergraduate research by providing formalized mentoring, academic programming, and increased research opportunities to nurture the academic skills and leadership potential of students from underrepresented backgrounds (see Figures 1 and 2). The program also was designed to help students pursue graduate scholarships and provide other educational supports specifically designated for underrepresented and first-generation students.

WMSURE is open to all William \& Mary students. The majority of participants (50 to 60 each year) are incoming students who are chosen by the admissions office to

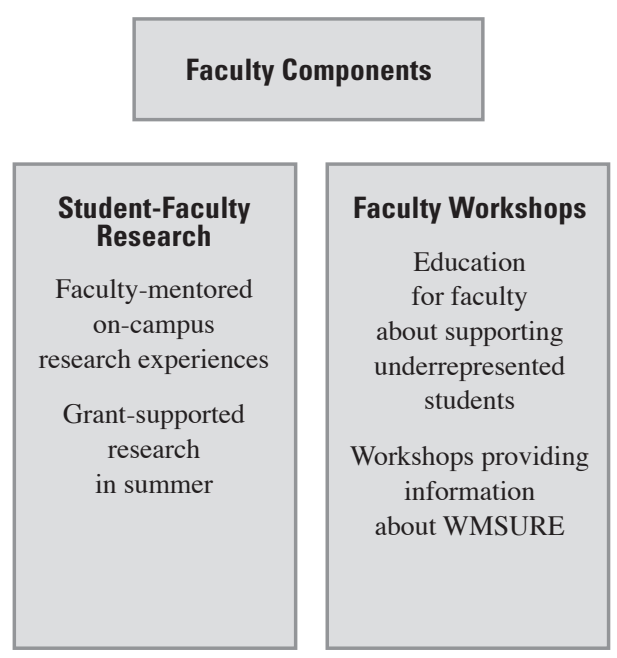

Fall 2018 | Volume 2 | Number 1 
FIGURE 2. The WMSURE Summer Research Showcase

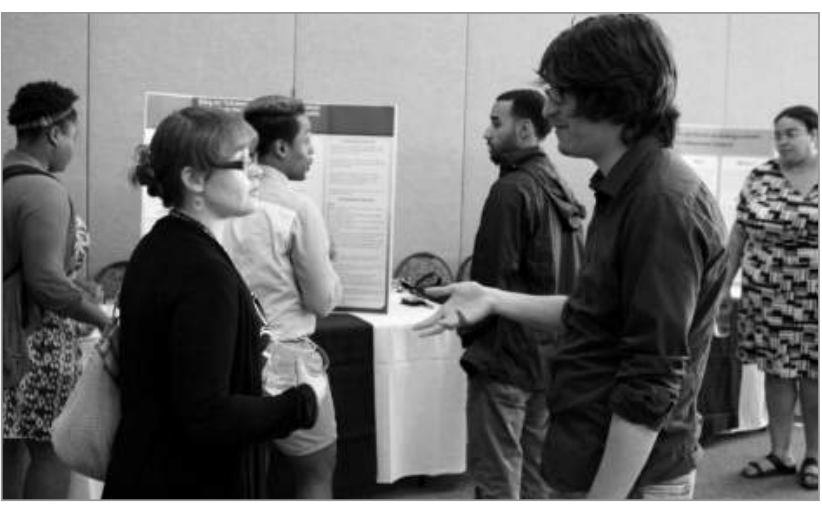

WMSURE scholars present their research.

receive the William \& Mary Scholarship, a merit-based scholarship that covers in-state tuition and is presented to academically distinguished students who will contribute to campus diversity or who have overcome unusual adversity and are members of underrepresented groups.

Although other colleges and universities have successfully designed and implemented programs focusing on underrepresented students that have led to student success, the authors used community-based research methods, codesigned with WMSURE students, to collect information from a representative sample of underrepresented students at William \& Mary to build a program that would address the specific needs of William \& Mary students. They worked with undergraduate students, including article coauthor Ebony Lambert, as research collaborators, identifying the most frequent components of and challenges to successful research experiences. Students were thus active throughout the research process, collaborating on research questions, research design, participant recruitment, data collection, and data analysis, as well as designing the subsequent WMSURE events.

Mixed-methods investigations were conducted using qualitative and quantitative measures to identify the successes of underrepresented students, as well as the barriers that they face at William \& Mary. Sixty-five students completed an online survey that assessed their experiences with research and mentorship and examined their perceptions of support from students and faculty. Psychological constructs of stereotype threat and solo status also were evaluated with validated measures. The responses of underrepresented students were compared to those of represented students. Stereotype threat is the experience faced by individuals when they think about the risk of confirming negative stereotypes about their group (Steele and Aronson 1995); this was measured to assess potential challenges to academic success. Solo status is the experience of being the only member of a particular sociocultural group in a setting such as a classroom (Lord and Saenz 1985), which can lead underrepresented students at a primarily white institution to feel that their perspectives are not acknowledged. In addition to these quantitative data, qualitative data were gathered via interviews and focus groups to get a richer sense of the empirical data. From these data, the specific needs of students were identified to create WMSURE. This mixed-methods approach allowed for personalization of the program around educational experiences, academic goals, and engagement of students throughout all four years of their college experience. To illustrate how these data were used to create the program, each element is described in the next section.

\section{WMSURE: Mentoring and Advising}

One of the first elements of the program recognized as critical was mentoring from faculty members. Data showed that 50 percent of underrepresented students stated that they did not receive mentorship from faculty. As mentorship is such an important part of academic success in college, WMSURE created a cohort of mentors from research faculty in different departments and programs throughout the campus. This group, designated WMSURE mentors, works directly with students (rather than staff, who are assigned to roles that focus on diversity, inclusion, or student success). Mentors are selected based on their previous record of support for students from underrepresented groups and are provided with professional development on specific issues reported by underrepresented students at William \& Mary. Some of these mentors also serve as first-year advisers to incoming scholars. These advisers initiate communication before the students' first year via email. In-person meetings commence once students arrive on campus, before classes begin (see Figure 3 ). This early contact allows students to establish a relationship with a faculty member whom they can ask both academic and personal questions. Furthermore, faculty mentors work to make policy changes on behalf of the students at the department and college levels.

\section{WMSURE: Weekly Student Workshops}

Data also suggested that weekly workshops, where students can obtain support and learn about issues in academia, would be important to mentoring and helping students become successful academic researchers. To this end, WMSURE developed weekly workshops addressing academic topics (e.g., writing, time management) based on the data (see Figure 4). Because research identified that underrepresented students at William \& Mary report discrimination and negative experiences on campus, several workshops also were created to address issues of solo status, stereotype threat, and racial discrimination, giving students multiple tools for use in confronting academic and social challenges. In addition to the collection of data via a survey, conversations were held with 
FIGURE 3. WMSURE Scholars in the WMSURE Lounge

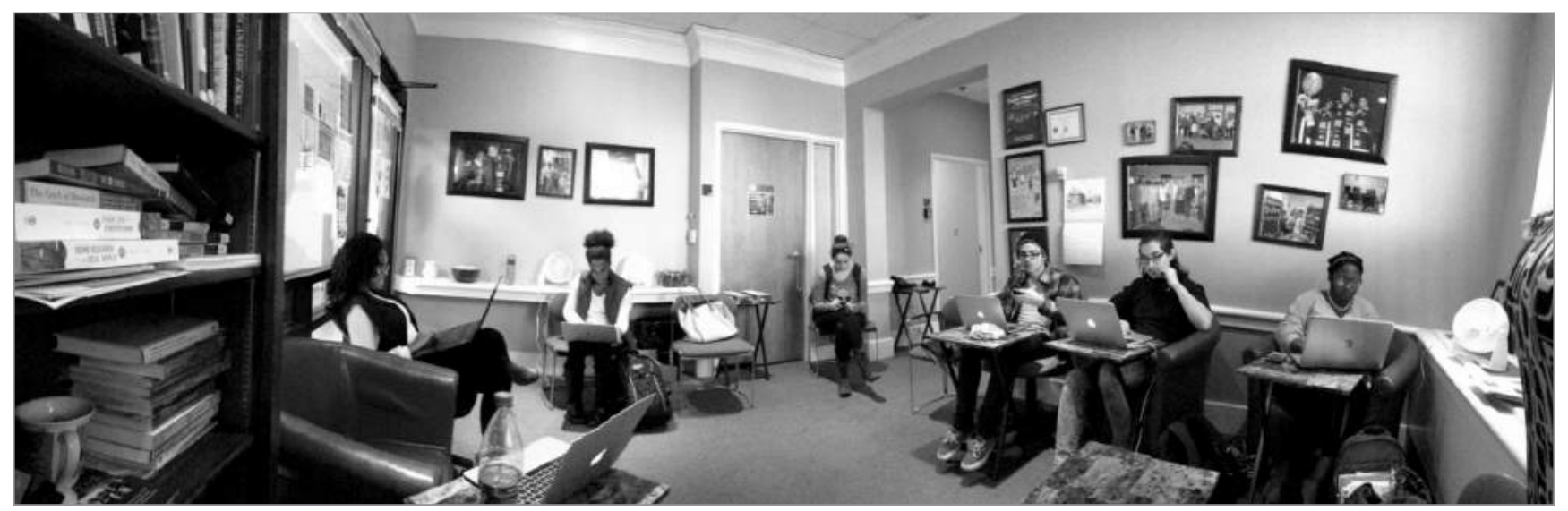

The space includes a meeting room and two large offices. The physical space gives the program cohesion and serves as an informal meeting space for students as well as a formal place to meet WMSURE faculty.

\section{FIGURE 4. A WMSURE Student Workshop}

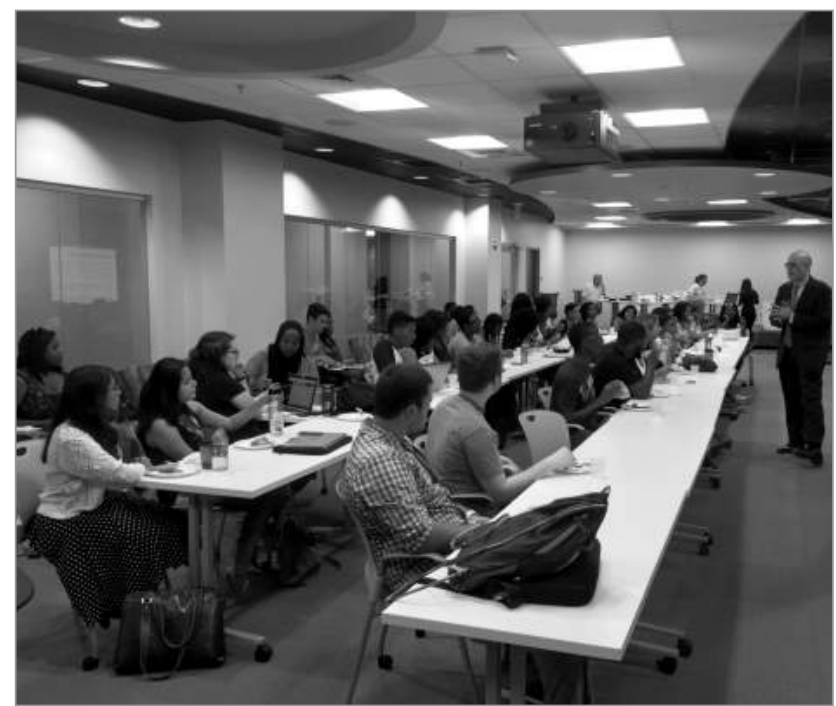

William \& Mary Provost Michael Halleran welcomes a new class of WMSURE scholars to the college.

underrepresented students in research spaces and classrooms, and during office hours, to assess their needs. Using this information as well as programming from similar programs across the country (e.g., Meyerhoff Scholars Program at the University of Maryland, Baltimore County 2018), the article authors also included workshops geared for students transitioning from high school to college. These workshops focused particularly on underrepresented minority and first-generation students, covering such topics as time and energy management, financial planning, library resources, finding and communicating with faculty advisers, writing research papers, presenting research, and preparing for graduate and professional school. Community-based learning and the use of research for the public good were emphasized to ensure that students could engage with the various social inequities they encountered as both scholars and active citizens. Workshops were scheduled to correspond to students' trajectories throughout the year, including deadlines for exams, research grants, graduate school applications, and declaration of majors. Each workshop included a presentation with a panel of faculty, staff, and/or students with expertise on the specific topic. This presentation was followed by small-group advising and networking, with the purpose of establishing an informal cohort of students and interacting with faculty in a less formal setting, which could lead to faculty-student research collaborations. This model continues to be used to the present, with the topics modified each year based on informal and formal feedback; students thus drive the workshops. WMSURE faculty mentors also attend the workshops and learn about topics affecting students.

\section{WMSURE: Faculty Workshops}

The data collected from students inform student programming and assist staff in counseling and student services as well as faculty in departments and programs that have had fewer successes with underrepresented students. In this way, a holistic approach is taken to helping students develop the tools needed to achieve their academic and social potential. This is important because, although many faculty learn how to teach their discipline in graduate school, they do not receive education relevant to understanding the needs of underrepresented students. Due to the importance of research in faculty members' work, providing compelling evidence of the issues faced by underrepresented students may be one way to help faculty understand these needs as it fits into their educational model. Examples of faculty workshop topics include reducing stereotype threat and solo status, mentoring underrepresented students, and helping students get started with undergraduate research. 


\section{WMSURE: Specific Impact of Programming}

With the support of the duPont Fund, the effectiveness of the program was assessed. To this end, a quantitative survey assessed the impact of WMSURE programming on its underrepresented scholars. In year 3 of WMSURE, a survey was conducted to explore outcomes of WMSURE programming using WMSURE students ( $n$ $=42 ; 85.7$ percent female; 40.5 percent black/African American, 4.8 percent Hispanic/Latinx, 23.8 percent multiracial; 2.4 percent American Indian, 2.4 percent Asian, 23.8 percent white, 2.4 percent Middle Eastern; 26.2 percent first-generation college students) and nonWMSURE students from the same underrepresented groups $(n=23 ; 55.6$ percent female; 21.7 percent black/ African American, 4.3 percent Hispanic/Latinx, 17.4 percent multiracial, 4.3 percent American Indian, 8.7 percent Asian, 34.8 percent white, 8.7 percent Middle Eastern; 23.8 percent first-generation college students). Participants reported how strongly they felt supported by the faculty and students at the college. They also indicated whether they had a faculty mentor on campus, the extent to which they were interested in research, and the degree to which they felt informed about research. They also were asked about their experiences with solo status and discrimination. Specifically, students were asked to report on the likelihood of experiencing discrimination based on their social group membership, as well as the frequency with which they experienced various discriminatory acts. Also assessed was the number of internal summer research grants received by WMSURE scholars, as an index of the number of scholars immersed in fulltime research.
In addition, qualitative data were collected to further assess the impact of WMSURE programming. A WMSURE graduate assistant and a WMSURE undergraduate student designed an interview protocol and conducted interviews with WMSURE students to learn about their experiences of solo status and how the negative impacts of solo status might be mitigated (Charity Hudley et al. 2017). In collaboration with the WMSURE undergraduate student, the graduate assistant analyzed the interview data thematically according to the actions, contexts, and impacts surrounding solo status described by the scholars (see Charity Hudley et al. 2017 for a comprehensive report of these qualitative methods).

\section{Quantitative Data}

As demonstrated in Table 1 , results indicated that WMSURE students felt significantly more supported by faculty than non-WMSURE students, but there were no differences in how the students felt supported by other students. WMSURE students were more likely to have a faculty mentor on campus than non-WMSURE students. WMSURE students reported being more interested in conducting research than non-WMSURE students. WMSURE students felt more informed about research than non-WMSURE students. WMSURE students felt that more discrimination existed against people with their ethnic background than non-WMSURE students, although WMSURE students reported no differences in how much discrimination they had personally experienced or in the support they had before coming to William \& Mary. WMSURE students reported having fewer students of their own race in their classes on average than nonWMSURE students.

TABLE 1. Outcome Variables for WMSURE and Non-WMSURE Students

\begin{tabular}{|c|c|c|c|}
\hline Variable & WMSURE students & Non-WMSURE students & Statistics \\
\hline Support from faculty & $3.65(0.08)$ & $3.04(0.18)$ & $t(74)=-3.58, p=0.001$ \\
\hline Support from students & $3.51(0.64)$ & $3.43(0.66)$ & $t(60)=-0.46, p=0.650$ \\
\hline Interest in conducting research & $3.37(0.48)$ & $2.95(0.15)$ & $t(68)=-2.05, p=0.046$ \\
\hline Informed about research & $2.89(0.13)$ & $2.30(0.21)$ & $t(65)=-2.52, p=0.014$ \\
\hline Faculty mentor on campus & $75.5 \%$ & $50.0 \%$ & $\chi^{2}=4.97, p=0.026$ \\
\hline How much discrimination exists & $2.84(0.14)$ & $2.30(0.21)$ & $t(61)=-2.00, p=0.050$ \\
\hline Discrimination personally experienced & $2.41(0.80)$ & $2.00(1.12)$ & $t(55)=-1.58, p=0.119$ \\
\hline Number of students of own race in class & $2.55(0.18)$ & $3.37(0.36)$ & $t(59)=2.27, p=0.027$ \\
\hline Support before coming to William \& Mary & $2.08(1.56)$ & $1.76(1.37)$ & $t(59)=-0.76, p=0.441$ \\
\hline
\end{tabular}

Note: Numbers represent means or percentages; number in parentheses are standard errors.

28 Scholarship and Practice of Undergraduate Research 
A total of 10 WMSURE students received summer research grants in 2013 and 2014, 15 received funding in 2015, and 15 received in-year funding in 2016. In addition, WMSURE scholars were funded by other sources, including individual faculty grants, National Science Foundation Research Experiences for Undergraduates (REU), and NASA.

\section{Qualitative Data}

Given that empirical evidence has demonstrated a causal relationship between increases in performance apprehension and decreases in performance level in underrepresented students who experience solo status (Sekaquaptewa and Thompson 2002; Sekaquaptewa, Waldman, and Thompson 2007), interviews were conducted to assess student perspectives on how to reduce the prevalence and impact of solo status. In this community-based approach, solo status was an important topic to examine; the relevance of solo status to the WMSURE community was apparent, as several WMSURE scholars chose solo status as a topic for their own research and for WMSURE workshops. In interviews, students were asked whether they were familiar with the term solo status; students' definitions were consistent with being underrepresented or being in an outgroup. In addition to knowing the term, all interviewed scholars described experiencing solo status. Although scholars identified some positive effects of solo status, there was a greater focus on negative effects throughout the interviews.

WMSURE scholars described solo status as an obstacle to academic success at William \& Mary (see Charity Hudley et al. 2017 for a comprehensive analysis of results). Scholars experienced solo status when their perspectives were not acknowledged, especially in academic contextsa type of intellectual solo status. WMSURE scholars explained that solo status can be mitigated when they connect with other students, faculty members, and/or the curriculum. For example, one scholar summarized this need:

I think for African Americans to be better represented, it's not a matter of throwing financial aid at them ... I think that it's more important that they get that education once they get to William and Mary, they're going to have those connections, and that they feel like they're part of that community that they're joining, to be able to be better represented, because they need to be able to be seen and be heard and you have to really nurture that feeling when they're coming to college.

Increasing the number of underrepresented students who pursue research experiences, as well as the quality of those experiences, has been imperative to the goals of WMSURE, as it aims to ensure that students feel that they are a part of the William \& Mary academic community.

Scholars explained that as their comfort levels in class and with faculty increased, the negative effects of solo status were mitigated. When underrepresented students face a longer adjustment period to academic contexts than other students, inequities are created in terms of those who have immediate access to opportunities for working with faculty. Some scholars explained that their peers who did not participate in WMSURE may not have been able to adjust to solo status in classes. WMSURE has addressed this challenge by holding workshops that provide prospective students with an understanding of research and ensure that incoming students already have familiarity with the research process. Participation in WMSURE has increased since the implementation of these workshops.

\section{Case Studies: Focus on the Individual Scholar}

The profiles of two students, WMSURE Scholar 1 (2013) and WMSURE Scholar 2 (2015), illustrate the impact of WMSURE on educational equity and inclusion. At the heart of WMSURE has been the principle that each individual student matters, so their stories represent that mission. For faculty advisers mentoring students during their research experiences, the case studies illustrate the importance of understanding the full scope of students' lives and experiences. These models are especially important for faculty who come from different backgrounds than WMSURE students. Faculty learn that the precollegiate experiences of students play a big role in their understanding of available research opportunities and whether such opportunities are actually created for them. Faculty are encouraged to talk with students with these points in mind and to present opportunities to them. The case studies also provided a sense of the postcollege opportunities obtained by WMSURE students and the role of WMSURE participation and research in their experiences after graduation.

Scholar 1 is an example of a scholar who participated in a middle school program aimed at increasing the academic success of high-achieving, underrepresented minorities in high school. She was one of the few African American students in her middle school's gifted and talented program and at her very selective high school. Scholar 1's excellence followed her to William \& Mary, where she was selected as a William \& Mary Scholar. For her honors thesis, she examined how autism affects the ability to acquire social language variation among African American children. Scholar 1 collected speech samples from African American families where one or more of the children were on the autism spectrum. Scholar 1's participation in WMSURE allowed her to form a cohort with other WMSURE scholars across disciplines that supported her in her research and graduate application process. Scholar 1 earned the award for the most outstanding Phi Beta Kappa initiate and was a consummate role model to other WMSURE participants. She went on to earn a master's of science degree in speech-language pathology at Vanderbilt University. Upon completion of her graduate study, the Vanderbilt Department of Hearing and Speech Science 
selected her to receive the award for outstanding clinical and academic achievements in speech-language pathology. She is now a speech-language pathologist at MD Anderson Cancer Center in Houston, Texas. She plans to focus her career in speech pathology on serving veterans with communication disorders.

Scholar 2 is an example of a white, first-generation student who found WMSURE and then became a mentor to other WMSURE students. He bravely reminded everyone of the experiences and needs of white, first-generation students who may go unnoticed, particularly on elite college campuses, where their race puts them in the dominant group, but their social status does not. Scholar 2 researched the history of coal mining to gain a better understanding of the issues facing his home state, writing an honors thesis on the history of the largest mining disaster in Europe. He received more than $\$ 12,000$ in grants to fund his research projects and helped expand the WMSURE programming to include workshops that addressed the social and academic challenges of transitioning to college for those from rural, low-income backgrounds. Following graduation, Scholar 2 wanted to expand college access in his home state. He returned home to help his family and took a position with the West Virginia Higher Education Commission, where he oversaw the successful expansion of financial aid initiatives aimed at increasing overall college enrollment and support among traditional and nontraditional students. He now attends the Harvard Graduate School of Education.

These case studies highlight how WMSURE programming supported high-achieving students from underrepresented backgrounds with particular research opportunities and programming, tailored by feedback, to their intellectual, social, and emotional needs. Using this community-participation, research-based model, these students were able to share their experiences with other students in a formal manner through their participation in the WMSURE program.

\section{Discussion}

The quantitative and qualitative data collected from WMSURE students provided a fuller sense of the nuanced challenges and barriers faced by underrepresented students at William \& Mary. The initial data collected helped inform the development of mentoring and advising services, workshops, faculty education, and research funding to support underrepresented undergraduates. Results suggest that institutions must provide comprehensive support for underrepresented scholars that includes these elements. The article authors encourage institutions to use community-based research to build a program that addresses the specific needs of their students. At William \& Mary, workshops were developed to ensure that students would find their perspectives acknowledged in a scholarly context, as WMSURE focuses on research in multiple disciplines with varied approaches, with particular attention to any voices, lenses, and perspectives that are not represented in current research paradigms. The workshops designed for WMSURE emphasized the importance of underrepresented perspectives in research, framing student perspectives that differ from current paradigms not as deficits but as strengths that should inform bodies of research across disciplines. Workshops also focus on topics-including solo status - that, although pertinent to the experiences of many underrepresented students, may go overlooked in other academic venues.

This study also provides insights into the characterization of the students and the program; however, these are limited based on the inability to determine a causal difference between groups. The preliminary evaluation suggests, however, that the WMSURE program may have improved outcomes of interest and that it presents a model that other schools can adapt through the use of community-based participatory research methods that allow for real-time mixed-methods analysis of the student experience.

\section{Lessons Learned and Future Directions}

As the WMSURE program is implemented and further developed, it is important to continue assessing its impact on current students. Success of the program is based on providing as many WMSURE scholars as possible with high-quality, faculty-mentored research experiences. The quality of these research experiences is continually assessed. This feedback is used to implement programming that enhances these experiences. Faculty advisers are educated about what they can do to improve facultystudent research. For example, a small cohort of faculty was chosen to work with two to four WMSURE students each year, supported by a grant from the Andrew W. Mellon Foundation; these faculty advisers meet as a group and also attend workshops on a regular basis to exchange information on improving their advisees' research experiences. Students' feelings of support and belonging on campus are assessed annually, and WMSURE programming is changed as necessary. Based on this feedback, for example, the number of workshops focused on dealing with race-related issues such as discrimination and campus climate was increased this year.

On a university-wide level, work with faculty continues to expand this model of undergraduate research across William \& Mary through enhancement of teaching that is focused on increasing underrepresented students' access to high-impact experiences such as undergraduate research. For example, presentations were given this year to several departments on mentoring underrepresented undergraduates, and a presentation on WMSURE was conducted for chairs of departments and programs in the arts and sciences. 
Additionally, the success of WMSURE has been shared with other institutions so that they may adapt the model for their underrepresented students. The research conducted with the students led to The Indispensable Guide to Undergraduate Research: Success in and Beyond College (Charity Hudley et al. 2017); more than 20 WMSURE students wrote vignettes for the book. This research-based guide seeks to advise first- and second-year college students, with a focus on the needs and interests of students who are underrepresented in college. In addition, the Andrew W. Mellon Foundation recently awarded William \& Mary a grant to allow for the expansion of WMSURE. This provides funding for a group of faculty for student-led projects, as well as the hiring of an associate director of the program to oversee day-to-day activities and expand the program. Work is underway on adapting the model at other institutions, such as the University of California Santa Barbara. The same evidence-based model will be used in which the experiences and needs of students and faculty are assessed, which will in turn inform the design of the program, including the nature of the research opportunities and workshops. Research will continue, especially, to examine student success, specifically with regard to undergraduate research opportunities, students' feelings of support and belonging, and students' desires to pursue graduate programs. Creating communication across institutions, including lessons learned, will allow refinement of the model for specific types of institutions. As research proceeds to examine ways to ensure student success, it is imperative that students and faculty from different universities work together to talk about supporting undergraduate research and to learn from each other.

\section{References}

Bearman, Steve, Stacy Blake-Beard, Laurie Hunt, and Faye J. Crosby. 2007. "Future Mentoring Research: Cutting Across Mentoring Themes and Contexts." In The Blackwell Handbook of Mentoring, ed. Tammy D. Allen and Lillian T. Eby, 519-547. Oxford: Blackwell. doi: 10.1111/b.9781405133739.2007.x

Blake-Beard, Stacy, Melissa L. Bayne, Faye J. Crosby, and Carol B. Muller. 2011. "Matching by Race and Gender in Mentoring Relationships: Keeping Our Eyes on the Prize." Journal of Social Issues 67: 622-643. doi: 10.1111/j.1540-4560.2011.01717.x

Charity Hudley, Anne H., Cheryl Dickter, Hannah A. Franz, Ebony Lambert, and Marvin Shelton. 2017. "Assessing and Mitigating Solo Status and Stereotype Threat among High Achieving African American Students: A Mixed-Methods Approach." Submitted for publication.

Clark, Richard A., Sherry L. Harden, and W. Brad Johnson. 2000. "Mentor Relationships in Clinical Psychology Doctoral Training: Results of a National Survey." Teaching of Psychology 27: 262-268. doi: 10.1207/s15328023top2704_04

Dreher, George F., and Taylor H. Cox Jr. 1996. "Race, Gender, and Opportunity: A Study of Compensation Attainment and the Establishment of Mentoring Relationships." Journal of Applied Psychology 81: 297-308. doi: 10.1037//0021-9010.81.3.297
Frierson, Henry T., Byron K. Hargrove, and Nicole R. Lewis. 1994. "Black Summer Research Students' Perceptions Related to Research Mentors' Race and Gender." Journal of College Student Development 35: 475-480.

Laden, Berta Vigil, and Linda Serra Hagedorn. 2000. "Job Satisfaction among Faculty of Color in Academe: Individual Survivors or Institutional Transformers?" New Directions for Institutional Research 2000(105): 57-66. doi: 10.1002/ir.10505

Lopatto, David. 2007. "Undergraduate Research Experiences Support Science Career Decisions and Active Learning." $C B E-$ Life Sciences Education 6: 297-306. doi: 10.1187/cbe.07-06-0039

Lord, Charles G., and Delia S. Saenz. 1985. "Memory Deficits and Memory Surfeits: Differential Cognitive Consequences of Tokenism for Tokens and Observers." Journal of Personality and Social Psychology 49: 918-926. doi: 10.1037//00223514.49.4.918

National Institutes of Health. 2015. "Racial and Ethnic Categories and Definitions for NIH Diversity Programs and for Other Reporting Purposes." https://grants.nih.gov/grants/guide/noticefiles/NOT-OD-15-089.html

National Science Foundation. 2014. "Women, Minorities, and Persons with Disabilities in Science and Engineering." https:// www.nsf.gov/statistics/2017/nsf17310/digest/introduction

Ortiz-Walters, Rowena, and Lucy L. Gilson. 2005. "Mentoring in Academia: An Examination of the Experiences of Protégés of Color." Journal of Vocational Behavior 67: 459-475. doi: 10.1016/j.jvb.2004.09.004

Phinney, Jean S., Cidhinnia M. Torres Campos, Delia M. Padilla Kallemeyn, and Chami Kim. 2011. "Processes and Outcomes of a Mentoring Program for Latino College Freshmen." Journal of Social Issues 67: 599-621. doi: 10.1111/j.15404560.2011.01716.x

Russell, Susan H., Mary P. Hancock, and James McCullough. 2007. "Benefits of Undergraduate Research Experiences." Science 316: 548-549. doi: 10.1126/science. 1140384

Sekaquaptewa, Denise, and Mischa Thompson. 2002. "The Differential Effects of Solo Status on Members of High- and LowStatus Groups." Personality and Social Psychology Bulletin 28: 694-707. doi: 10.1177/0146167202288013

Sekaquaptewa, Denise, Andrew Waldman, and Mischa Thompson. 2007. "Solo Status and Self-Construal: Being Distinctive Influences Racial Self-Construal and Performance Apprehension in African American Women." Cultural Diversity and Ethnic Minority Psychology 13: 321 doi: 10.1037/1099-9809.13.4.321

Smith, Janice Witt, Wanda J. Smith, and Steven E. Markham. 2000. "Diversity Issues in Mentoring Academic Faculty." Journal of Career Development 26: 251-262. doi: $10.1177 / 089484530002600402$

Steele, Claude M., and Joshua Aronson. 1995. "Stereotype Threat and the Intellectual Test Performance of African Americans." Journal of Personality and Social Psychology 69: 797. doi: 10.1037//0022-3514.69.5.797

University of Maryland, Baltimore County. 2018. "Meyerhoff Scholars Program.” https://meyerhoff.umbc.edu

Fall 2018 | Volume 2 | Number 1 
U.S. Department of Education. 2018. "Ronald E. McNair Postbaccalaureate Achievement Program." https://www2.ed.gov/programs/triomcnair/index.html

\section{Cheryl L. Dickter}

College of William \& Mary, cldickter@wm.edu

Cheryl L. Dickter is the University Professor for Teaching Excellence at the College of William and Mary. She is an associate professor in the Department of Psychological Sciences and a faculty affiliate of the Neuroscience Program and the Gender, Sexuality, and Women's Studies Program. Dickter has published more than 30 articles, books, and book chapters. She co-directs the William \& Mary Scholars Undergraduate Research Experience (WMSURE). Her work has been funded by the National Science Foundation and the National Institutes of Health. She is an associate editor for Social Affective and Cognitive Neuroscience.

Anne Charity Hudley is the North Hall Endowed Chair in the Linguistics of African America at the University of California, Santa Barbara, and director of undergraduate research for the College of Letters and Science. She is the coauthor of three books: The Indispensable
Guide to Undergraduate Research: Success in and Beyond College, Understanding English Language Variation in U.S. Schools, and We Do Language: English Language Variation in the Secondary English Classroom. She also is the author or coauthor of more than 25 articles and book chapters concerning the relationship between English language variation and $\mathrm{K}-16$ educational practices and policies. Charity Hudley is a member of the Executive Committee of the Linguistic Society of America.

Hannah A. Franz is a PhD candidate in educational policy, planning, and leadership at the College of William \& Mary. She was a graduate assistant for WMSURE from 2013 until 2017. She earned an MS Ed in reading, writing, and literacy from the University of Pennsylvania and an MA in sociolinguistics from North Carolina State University.

Ebony A. Lambert is a PhD student in health psychology at Virginia Commonwealth University. She served as an undergraduate research fellow for WMSURE from 2013 until 2016. She graduated from the College of William \& Mary in 2016 with a BA in psychology and Africana studies.

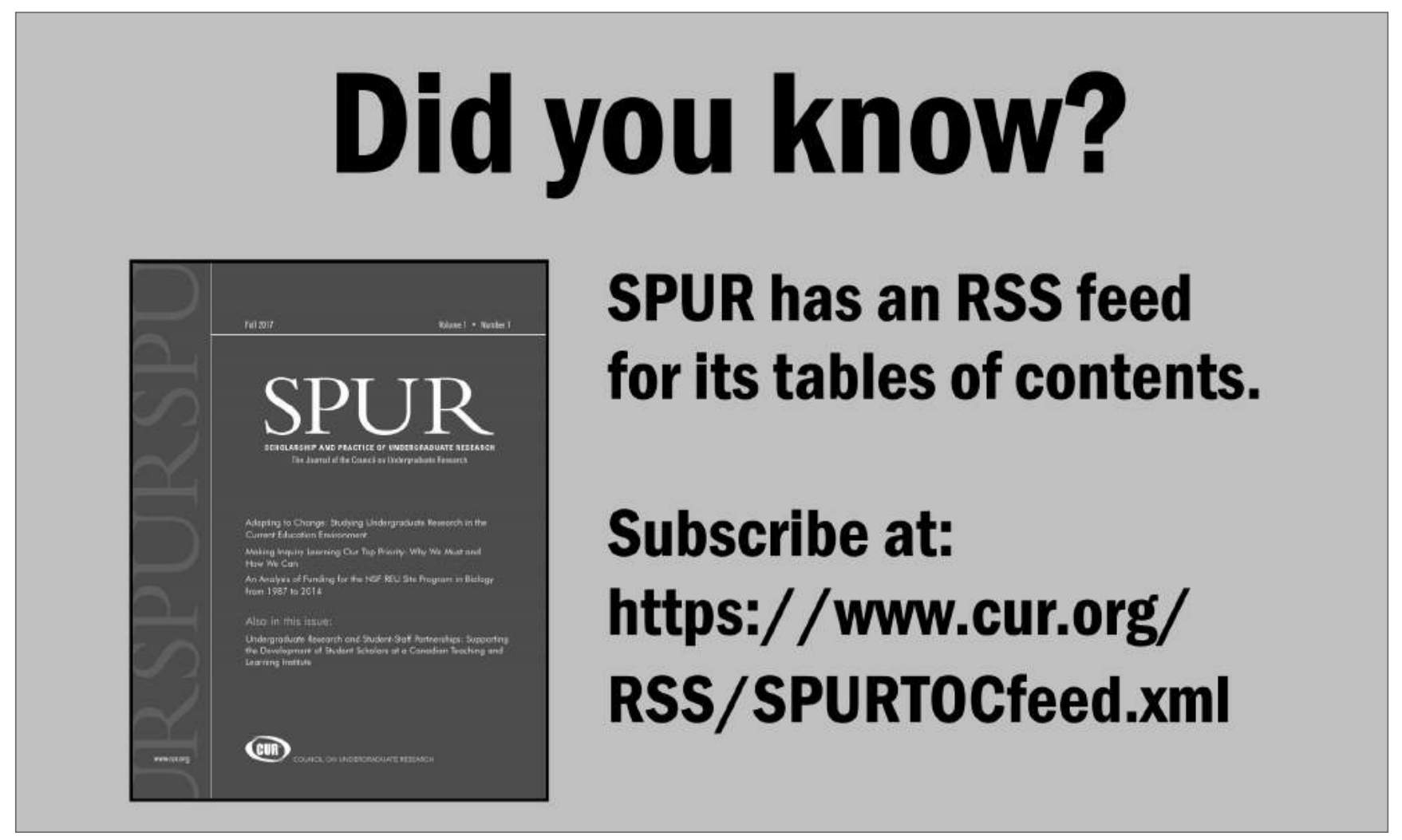

